\title{
Endocrine cells in atresic chick embryo intestine: histochemical and immunohistochemical study
}

\author{
R. Vaccaro, ${ }^{1}$ E. Parisi Salvi, ${ }^{1}$ I. Nofroni, ${ }^{2}$ I. D'Este, ${ }^{1}$ S.M. Baglaj, ${ }^{3}$ T. Renda ${ }^{1+}$ \\ ${ }^{1}$ Department of Human Anatomy, Sapienza University of Rome, Rome, Italy; ${ }^{2}$ Statistics Section, \\ Department of Experimental Medicine, Sapienza University of Rome, Rome, Italy; ${ }^{3}$ Department of \\ Pediatric Surgery, Wroclaw Medical University, Poland
}

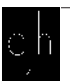

(C2009 European Journal of Histochemistry

Intestinal motility disorders are an important problem in the postoperative management of patients with intestinal atresia. Intestinal motility could be initiated by luminal factors that activate intrinsic and extrinsic primary afferent nerves involved in the peristaltic reflex. Endocrine cells act as a key point, because they transfer information regarding the intestinal contents and intraluminal pressure to nerve fibers lying in close proximity to the basolateral surface of the epithelium. In chick embryo, experimental intestinal atresia is associated with disorders in the development of the enteric nervous system, related to the severity of intestinal dilation. Our aim was to investigate the distribution pattern of endocrine cells in the developing endocrine system of chick embryo small intestine with experimentally-induced atresia on day 12 and on day 16 . Changes in enteroendocrine population were examined in gut specimens (excised proximal and distal to the atresia) from experimental embryos 19 days old and in control sham-operated chick embryos at the same age. Sections from proximal and distal bowel and control bowel were stained with Grimelius silver stain, a valuable histochemical method for detecting the argyrophil and argentophilic cells, and with an immunohistochemical procedure for detecting serotonin and neurotensin immunoreactive cells. In chick embryo proximal bowel, intestinal dilation differed in the various embryos. We found significantly higher enteroendocrine cell counts in proximal bowel than in distal and control bowel. The differences depended on the precociousness of surgery and the severity of dilation. Considering the major contribution of enteroendocrine cells to the peristaltic reflex, our data may help to explain the pathogenesis of motility disorders related to intestinal atresia.

Key words: avian embryo, ontogeny, endocrine cells, intestinal atresia, immunohistochemistry.

Correspondence: E. Parisi Salvi,

Department of Human Anatomy, Sapienza University of Rome, Via Alfonso Borelli, 50, 00161 Rome, Italy

Tel.: +39.0649918128.

Fax: +39.0649918127

E-mail: ebe.parisi@uniroma1.it

Paper accepted on June 29, 2009

European Journal of Histochemistry

2009; vol. 53 issue 3 (July-September): 143-150
I ntestinal motility disorders are a common complication after surgery for neonatal intestinal atresia. Although intestinal atresia causes alterations in the enteric nervous system, especially in its inner structures as nervous fibers in the mucosa, submucous and deep muscular plexuses (Masumoto et al., 1999; Schoemberg and Kluth, 2002; Parisi Salvi et al., 2004; Fiegel et al., 2006), the physiopathology of the motility disorders remains unknown. It is a complex process because of the multiplicity of factors implicated in the genesis of the peristaltic reflex and the overlap between the developing enteric neuroendocrine system and intestinal atresia. Moreover, the relationships cause/ effect between changes of neuroendocrine organization induced by atresia and the dilation of proximal bowel are not focused yet.

Intestinal motility and secretion are initiated by luminal factors that activate intrinsic and extrinsic primary afferent nerves involved in peristaltic and secretory reflexes (Furness et al., 1999; Gershon, 1999). The reflex circuitry of the enteric nervous system can be activated by a variety of stimuli, including the chemical composition of the luminal contents and mechanical stimuli. The nerve terminals of intrinsic primary afferent neurons do not extend into the lumen of the gastrointestinal tract. Rather, enteroendocrine cells, whose apical surface are exposed to the lumen of the gastrointestinal tract, act as sensory transducers and release substances including serotonin from their basolateral surfaces (Gershon, 1999; Bertrand et al., 2000; Zhu et al., 2001). Therefore, mucosal enterochromaffin cells, which act as sensory transducers activating intrinsic and extrinsic primary afferent nerves, could play a significant role in the development of intestinal motility disorders. Moreover, serotoninergic signaling abnormalities have also been implicated in the pathogenesis of functional 
bowel diseases (Gershon and Tack, 2007).

As concerns neurotensin, its physiological functions include stimulation of colonic motility and inhibition of small bowel and gastric motility (Reinecke, 1985; Rothstein and Ouyang, 1989; Unno et al., 1999; Zhao and Pothoulakis, 2006). Trophic and regulatory effects of neurotensin on numerous tissues of the gastrointestinal tracts in physiological and pathological conditions were also demonstrated (Izukura et al., 1992; KulinskaNiedziela and Paluszak, 1997; 0'Hara et al., 2004; Assimakopoulos et al., 2006; Wang et al., 2006; Zhao and Pothoulakis, 2006; Akcan et al., 2008). No data are available on changes, induced by atresia, on endocrine cell distribution pattern.

The chick model is a useful research tool for investigating the pathogenesis of congenital gastrointestinal diseases (Tibboel et al., 1979; Masumoto et al., 1999). We used an experimental chick model (Baglaj et al., 2001) that reproduces the most common type of intestinal atresia found in newborn babies (type II intestinal atresia) (Grosfeld et al., 1979) by transforming a jejunoileal segment into a fibrotic cord that separates two blind ends proximal and distal to the atresic stump. In this model we have just investigated the development of the enteric nervous system (Parisi Salvi et al., 2004). Our aim was to investigate the distribution of enteroendocrine cell population with particular regards to serotonin and neurotensin immunoreactive cells in atresic embryos.

\section{Materials and Methods}

\section{Animals and preoperative preparation}

As the experimental model of intestinal atresia we used 49 chick embryos (White Leghorn, Gallus domesticus). The eggs were incubated at temperatures from $37.5^{\circ} \mathrm{C}$ to $37.6^{\circ} \mathrm{C}$ and relative $70 \%$ air humidity in a Bios-Midi incubator (Sedlacany, Czech Republic) with automatic temperature and humidity control, and two hourly tilting.

\section{Operative method}

Surgical manipulations in chick embryos were done on day 12 (D 12) and D 16 (stage 38, and 42 according to Hamburger \& Hamilton, 1951) under aseptic conditions and stereoscopic control (Stemi 2000C, Zeiss, Germany). After candling the egg with an ovoscope, the air chamber was identified, punctured and aspirated. A small oval hole of 1.5 $\mathrm{cm}$ was cut off at the blunt end. The lining shell membranes were partly removed and the chorioallantoic membrane was gently opened in an avascular plane. The omphalo-mesenteric artery was identified and used as a landmark for carefully grasping the umbilical stalk. Under visual control, the amniotic membrane and the umbilical stalk wall were opened directly over the midgut loops protruding at this stage outside the abdominal cavity. One of the distally located loops was pulled gently outside the stalk. The mesentery supplying a small intestinal segment 7-8 $\mathrm{mm}$ in length was electrocoagulated using a sharp-pointed microsurgical bipolar coagulator pincette (GN 060 Aesculap, Tuttlingen, Germany). The most distal arterial arcade running parallel close to the mesenteric border of that segment was also coagulated. Throughout surgery care was taken not to grasp or squeeze the intestinal loop itself. Once mesenteric manipulation was complete the bowel loop was repositioned into the umbilical stalk. Finally, the hole in the eggshell was closed with a sterile transparent semi-permeable adhesive membrane and incubation was resumed. If the intestine was inadvertently perforated during surgery the embryo was excluded from further study.

Chick embryos were assigned to one of the following three groups:

- sham-operated embryos $(n=14)$ underwent only brief grasping of the midgut loop outside the umbilical stalk, on D 12 or D 16, with no manipulation of the mesenteric vessels.

- atresic embryos $(n=19)$ that underwent the complete surgical procedure on D 12 for induction of vascular catastrophe.

- atresic embryos $(n=16)$ that underwent the complete surgical procedure on D 16.

On D 19 all embryos were delivered from the shell. The extraembryonic membranes were carefully removed and the umbilical ring was widely opened to expose to the abdominal cavity. The macroscopic appearance of the small intestine, its continuity and any pathologic changes within the peritoneal cavity were assessed. The type and topography of intestinal atresia were examined in the experimental group.

\section{Tissue preparation}

From each of the 16 survived embryos with experimentally-induced intestinal atresia (Table 1) 
Table 1. Number of sham-operated and atresic embryos collected

\begin{tabular}{lcccc}
\hline Sham-operated embryos & \multicolumn{3}{c}{ Atresic embryos } \\
\hline $\begin{array}{c}\text { Operated on D 12 } \\
\text { moderately } \\
\text { dilated }\end{array}$ & $\begin{array}{c}\text { severely } \\
\text { dilated }\end{array}$ & $\begin{array}{c}\text { Operated on D } 16 \\
\text { moderately } \\
\text { dilated }\end{array}$ & $\begin{array}{c}\text { severely } \\
\text { dilated }\end{array}$ \\
\hline $\mathrm{n}=10$ & $\mathrm{n}=2$ & $\mathrm{n}=5$ & $\mathrm{n}=4$ & $\mathrm{n}=5$ \\
\hline
\end{tabular}

(survival rate $=45.7 \%$ ) a small bowel specimen $2.5 \mathrm{~cm}$ in length proximal to the atresic tract and a specimen $1.5 \mathrm{~cm}$ in length distal to the atresic tract were excised. To exclude tracts possibly damaged by ischemia, we left a stump $5 \mathrm{~mm}$ in length at the proximal and distal ends of the atresic tract. Equivalent small bowel specimens were excised from 10 sham-operated embryos (survival rate $=$ $71.4 \%$ ). Specimens were fixed in cold PAF mixture of $4 \%$ paraformaldehyde and $2 \%$ picric acid in 0.1 $\mathrm{M}$ phosphate buffer (PB), pH 7.3 overnight, then washed, dehydrated, paraffin embedded and cut into 5-7 $\mu \mathrm{m}$ thick serial sections that were mounted on albumin-coated slides.

\section{Histochemical study}

Dewaxed sections from proximal and distal bowel and control bowel were stained with Grimelius silver stain (Grimelius and Wilander, 1980).

\section{Immunohistochemical study}

In order to block endogenous peroxidase activity, sections were pretreated with PB containing $0.1 \%$ sodium azide and $0.8 \% \mathrm{NaCl}$ (PBS) and $0.3 \%$ $\mathrm{H} 202$ ( $\mathrm{Li}$ et al., 1987). To avoid aspecific antibody binding sections were preincubated in normal goat serum diluted $1: 30$ in PBS containing $1 \%$ bovine serum albumin, (BSA, Sigma, USA). Sections were incubated in a moist chamber for $24 \mathrm{~h}$ at room temperature with polyclonal antisera to: serotonin (Chemicon, USA) diluted $1: 15,000$ and neurotensin (Milab) diluted 1:15,000. Sections were then incubated for $1 \mathrm{~h}$ at room temperature with biotinylated goat anti-rabbit immunoglobulin diluted $1: 1,000$ with PBS/BSA and then incubated for $45 \mathrm{~min}$ at room temperature with streptavidinbiotin-peroxidase complex ( $A B C$, Elite Kit; Vector Laboratories) diluted 1:2,000 with $0.05 \mathrm{M}$ Tris$\mathrm{HCl}$ buffer, $\mathrm{pH}$ 7.6, containing $0.8 \% \mathrm{NaCl}$. Peroxidase activity was visualized in a $3-\mathrm{min}$ reaction with a mixture containing $0.04 \% 3-3$ diaminobenzidine tetrahydrochloride (DAB; Fluka, Buchs, Switzerland), $0.4 \%$ nickel-ammonium sulfate, and $0.003 \% \mathrm{H}_{2} \mathrm{O}_{2}$ in $0.05 \mathrm{M}$ Tris- $\mathrm{HCl}$ buffer, $\mathrm{pH}$ 7.6. For specificity controls the primary antiserum was substituted with PBS alone or with suitably diluted normal rabbit serum.

Fields of analysis were digitalized on the screen, the linear extent of the mucosal surface was measured in control and experimental specimens as a straight line, and the number of stained cells was counted. The ratio between numbers of stained cells/mm of mucosal surface was calculated, and indicated as a frequency per $\mathrm{mm}$.

\section{Statistical analysis}

The mean density of stained cells was determined by sampling from four-eight sections in each segment. Results are expressed as median for each group. Statistical comparisons were conducted with non parametric tests because the data were not normally distributed. Comparison between values of proximal versus distal bowel was made using paired Wilcoxon signed ranks test, whereas comparison between proximal and distal versus control bowel was made using Mann-Whitney test. A value of $p<0.05$ was considered statistically significant.

\section{Results}

\section{Morphological findings}

Considering that the proximal bowel showed a different dilation degree in the various embryos, we measured the circumference of proximal and distal bowel and control sections. Distal and control bowel showed a circumference of 9-12 mm. Proximal bowel showed a dilation degree from $10 \%$ till up to $100 \%$. We divided specimens into two groups based on the degree of dilation of the proximal bowel: moderately dilated (up till $25 \%$ of dilation) and severely dilated (over $26 \%$ of dilation) (Table 1).

On the whole we found a different morphological appearance in the proximal bowel in comparison to distal and control bowel; our findings were related to the dilation degree. In severely dilated proximal bowel we found stubby intestinal villi in a whole flattened intestinal wall (Figure 1). In moderately dilated proximal bowel and in distal bowel we did not find detectable morphological differences in comparison to control bowel. 


\section{Enteroendocrine cells}

We did not find any difference on the distribution of enteroendocrine cells between sham-operated on D 12 and D 16, so both were considered as just one control group.

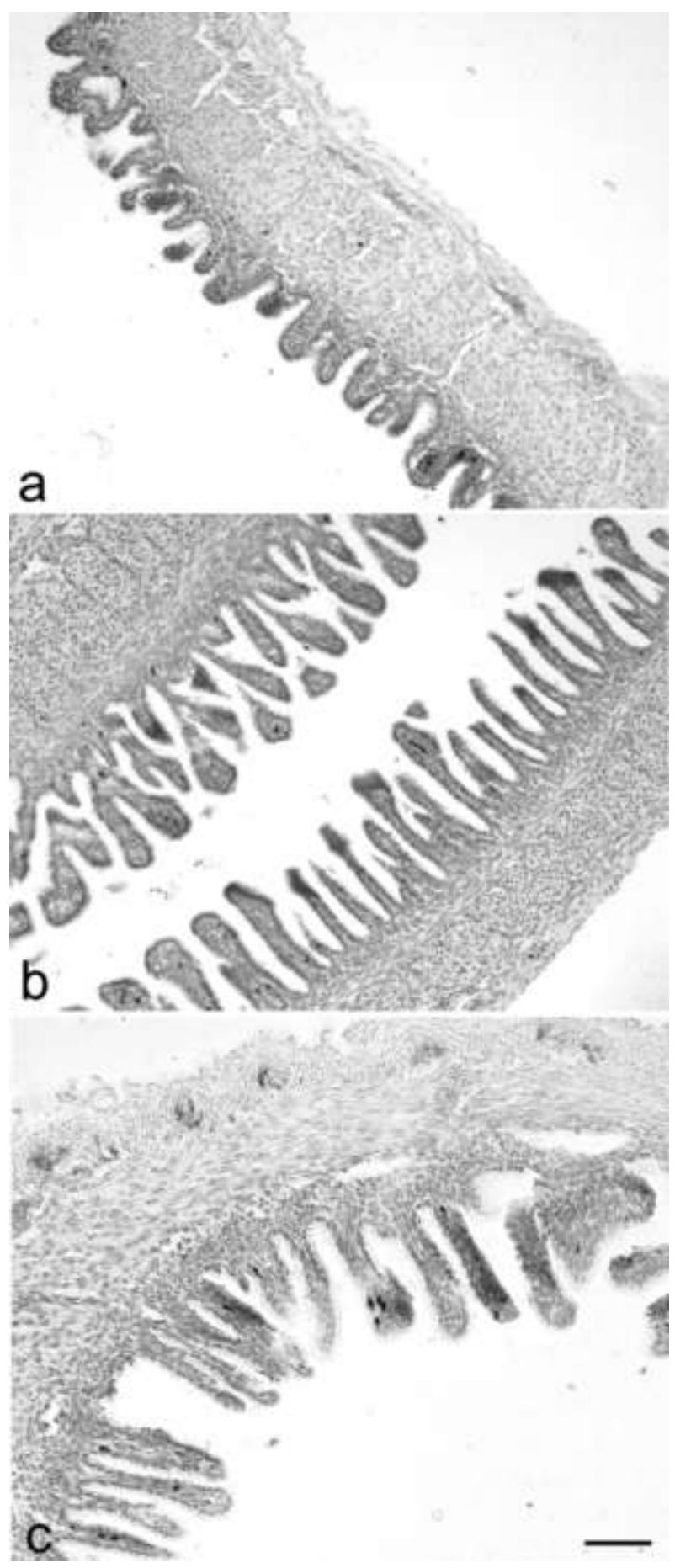

Figure 1. Grimelius silver stained bowel. Stubby intestinal villi are seen in severely dilated proximal bowel (a) in comparison with distal bowel (b) of chick embryo operated on D 12 and control bowel (c). Scale bar $=200 \mu \mathrm{m}$.
Grimelius silver stain. In proximal bowel we found a significant increase of cell number, mainly in chick embryos operated on D 12 (Figure 2, 3a).

Serotonin. Same trend was found within serotonin immunoreactive cell population. In proximal bowel we found a remarkable increase of cell number, especially significant in chick embryos operated on $D 12$ (Figure 2, 3b). In distal bowel of chick embryos operated on D 16 we found a significant decrease of cell number, compared to controls (Figure 2b).

Neurotensin. Neurotensin immunoreactive cells remarkably increased in the proximal bowel compared to the distal bowel (Figure 2,3c). There were no significant differences in distal bowel compared to control.
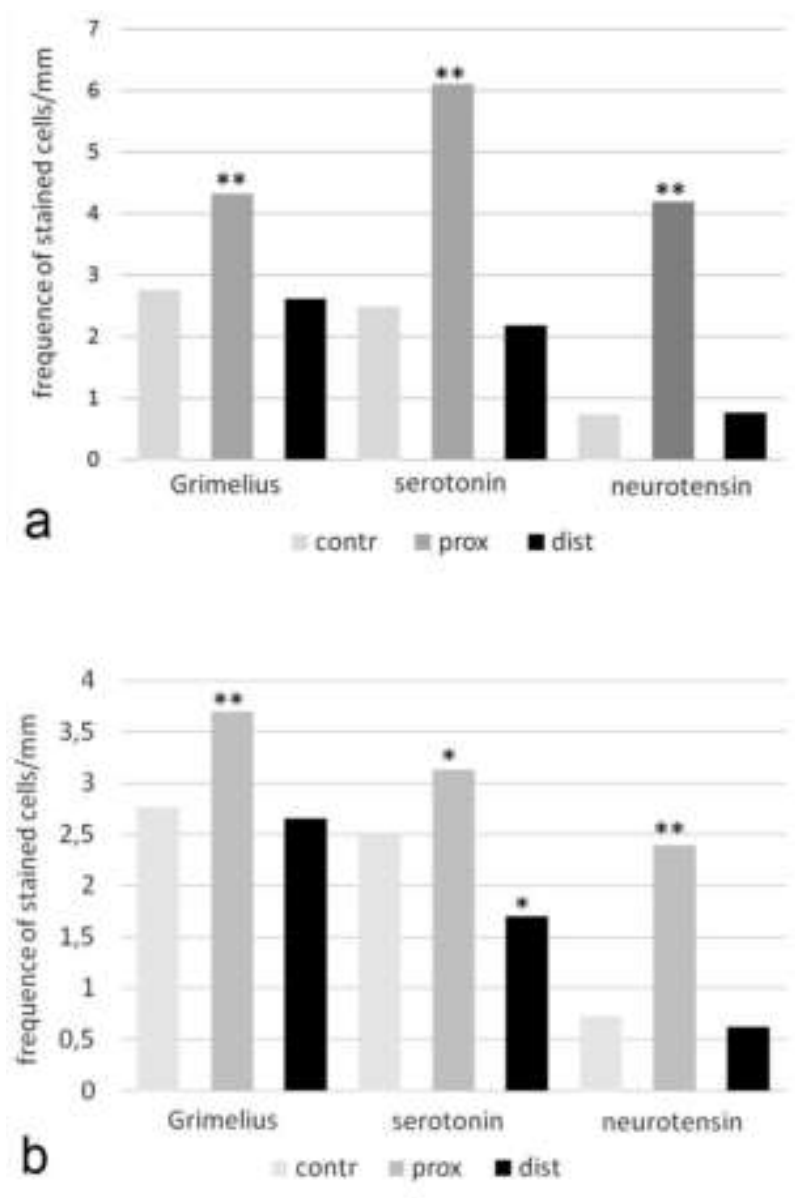

Figure 2. Surgery on D12 (a) and on D16 (b). Median values of frequency/mm of stained cells. Contr, control bowel; prox, proximal bowel; dist, distal bowel. *significant $(p<0.05)$; ** very significant $(p<0.0001)$. 


\section{Results related to the dilation degree}

Grimelius silver stain. The increase of cell number in proximal bowel was significant in severely dilated specimens in both embryos operated on D 12 and $D$ 16 , but not significant in moderately dilated specimens (Figure 4).

a

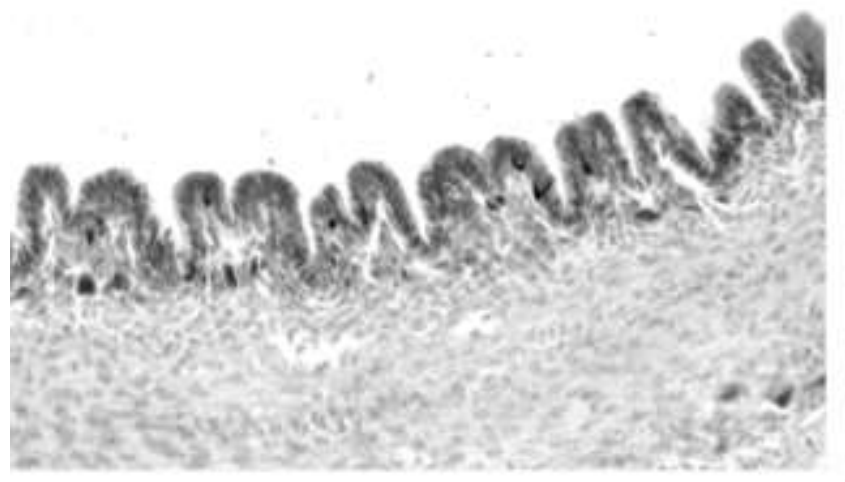

b
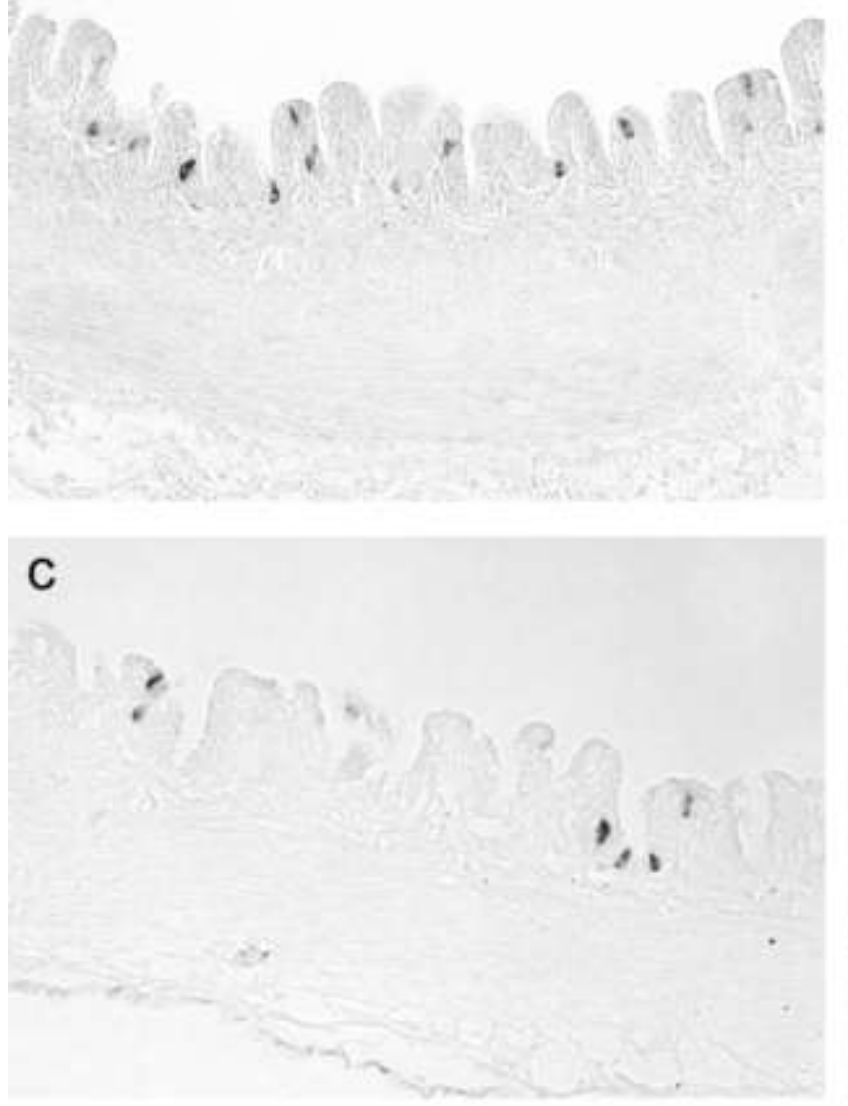

Serotonin. Significant increase of cell number in severely and moderately dilated proximal bowel of chick embryos operated on D 12 and in severely dilated proximal bowel of chick embryos operated on D 16 (Figure 5).

Neurotensin. Significant increase of cell number in severely dilated, but not in moderately dilated prox-
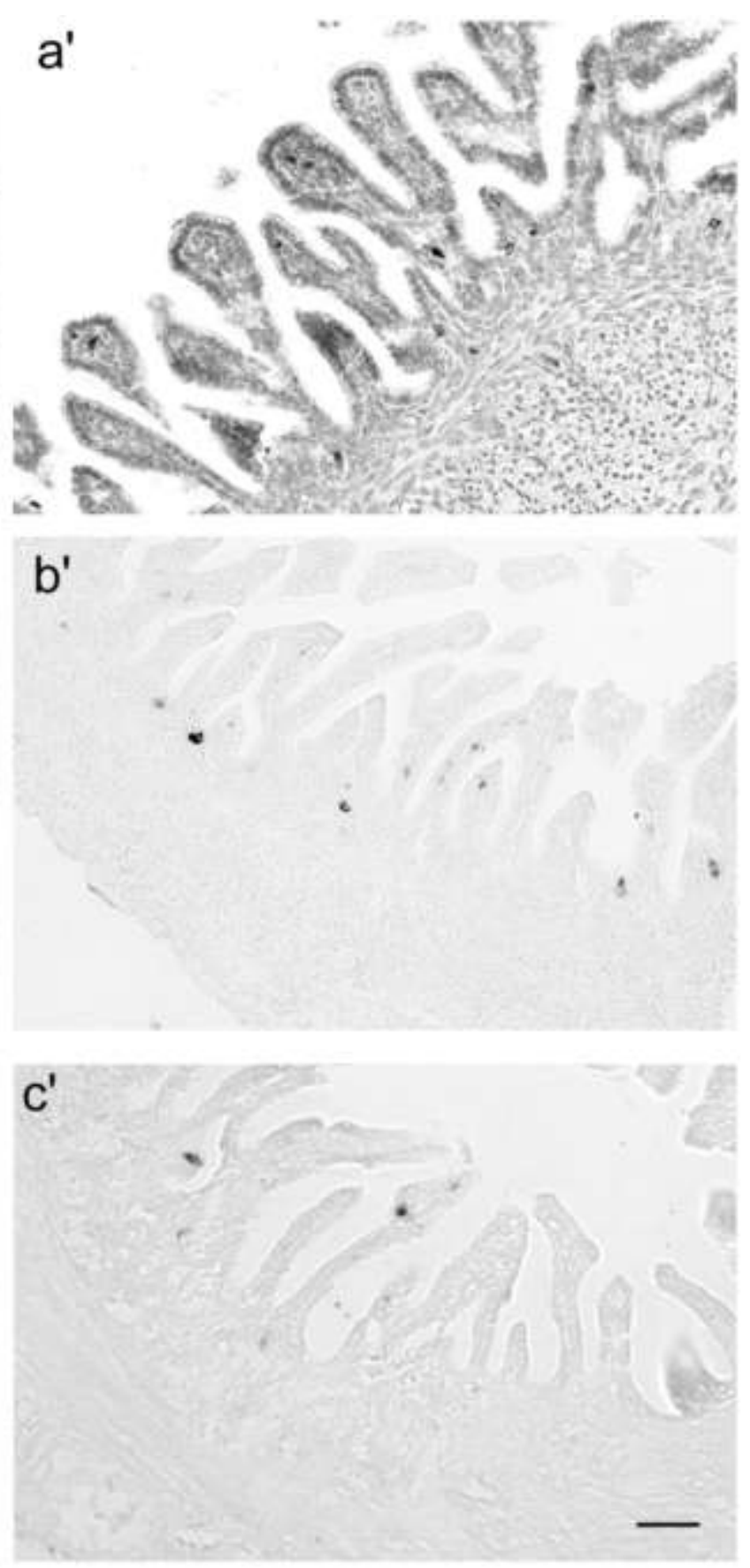

Figure 3. Enteroendocrine cells in severely dilated proximal and distal bowel of chick embryos operated on $D$ 12. Grimelius silver stained cells $\left(a, a^{\prime}\right)$, serotonin $\left(b, b^{\prime}\right)$ and neurotensin $\left(c, c^{\prime}\right)$ immunoreactive cells in proximal $(a, b, c)$ and distal $\left(a^{\prime}, b^{\prime}, c^{\prime}\right)$ bowel. Scale bar = $100 \mu \mathrm{m}$. 
imal bowel of both chick embryos operated on D 12 and D 16 (Figure 6).

\section{Discussion}

As a general rule we found an increase of the whole enteroendocrine cell population in the proximal bowel compared to distal and control bowel. This increase depended on the precociousness of the surgery and the severity of the dilation of proximal bowel. However, previous works showed the relation between the degree of dilation and the severity of changes in the enteric nervous system (Masumoto et al., 1999; Parisi Salvi et al., 2004).

Enteroendocrine cells appear early in the chick embryo umbilical loop on D 10-D 11 (Romanoff, 1960), then they spread cranially and caudally. Serotonin immunoreactive cells appear later on D 11 in the upper and on D 14 in the lower ileum (Salvi and Renda, 1986; 1989a), are few scattered cells until $D$ 15, and then they rapidly increase up to hatching. Finally, neurotensin
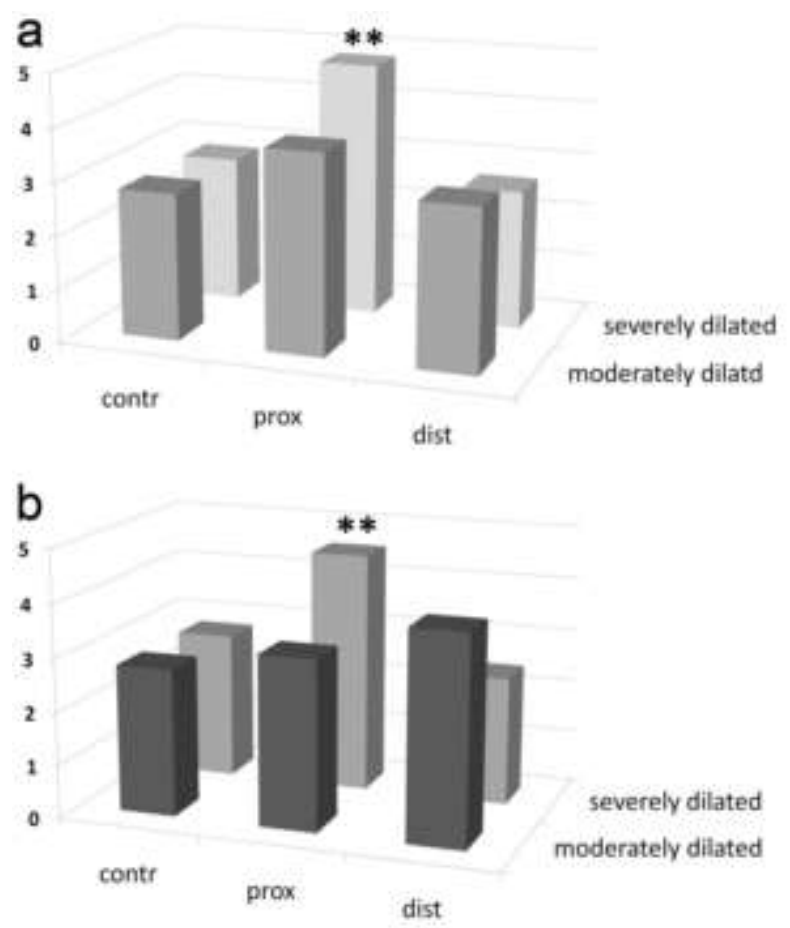

Figure 4. Surgery on D12 (a) and on D16 (b). Median values of frequency $/ \mathbf{m m}$ of Grimelius stained cells. Units on the $Y$ axis indicate number of stained cells/mm. Contr, control bowel; prox, proximal bowel; dist, distal bowel.

**Very significant $(p<0.0001)$.
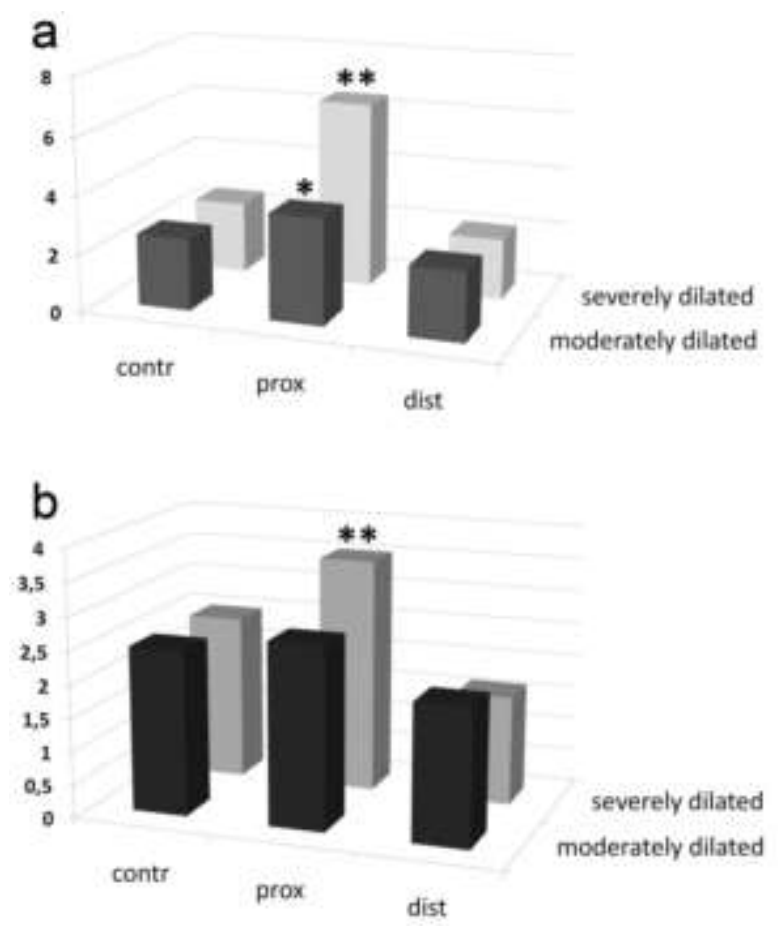

Figure 5. Surgery on D12 (a) and on D16 (b). Median values of frequency $/ \mathrm{mm}$ of serotonin immunoreactive cells. Units on the $Y$ axis indicate number of stained cells $/ \mathrm{mm}$. Contr, control bowel; prox, proximal bowel; dist, distal bowel.

*Significant $(p<0.05)$; ** very significant $(p<0.0001)$. 
immunoreactive cells appear on D 13 in the upper and on D 17 in the lower ileum (Salvi and Renda, $1989 \mathrm{~b})$ and they are very rare in adult chicken (Atoji et al., 1994). In the distal bowel endocrine cells tend to decrease in comparison with control bowel, but only in distal bowel operated on D 16 the decrease of serotonin immunoreactive population is significant. Therefore, distal bowel also undergoes a change in the distribution pattern of enteroendocrine cells, despite its normal morphological appearance. On the other hand, previous studies using neuronal markers point the asynchronic development of the myenteric plexus, which appears delayed below the obstacle and accelerated above in human intestinal atresic specimens (Khen et al., 2004). The increase of endocrine cell population in severely dilated proximal bowel correlates with a disorganization and reduction of peptidegic nerve network that we found at a later embryonic age (Parisi Salvi et al., 2004). A close relation between endocrine cells and nerve network in abnormal functioning bowel was already shown in the colon of patients with Hirschsprung's disease where the number of endocrine cells in the aganglionic segment was significantly increased, compared with the ganglionic segment (Soeda et al., 1993).

Grimelius silver stain shows an increase of the whole enteroendocrine population. In severely dilated proximal bowel of chick embryo operated on $\mathrm{D} 12$ we found that the serotonin immunoreactive cells were more numerous compared with the silver stained cells. This finding appeared as a nonsense datum, since serotonin immunoreactive cell population is only a group of the whole silver stained enteroendocrine cell population. Grimelius silver method stains structural components of the granules, whereas immunohistochemical method stains serotonin regardless of its storage in secretory granules or release into the cytoplasmic matrix. On the other hand, after raising the intraluminal pressure, serotonin, normally stored in the secretory granules of enterochromaffin cells, appears to be released into the cytoplasmic matrix and then diffused or transported into the intestinal lumen (Fujimiya et al., 1997) and the luminal release of serotonin increase with elevated intraluminal pressure. Moreover, enteroendocrine cell population revealed by serotonin immunohistochemistry but not by conventional techniques consists, at least in part, of less mature cells than those identified by conventional techniques such as Grimelius silver stain (Inokuchi et al., 1984, Fujimiya et al., 1995).

Neurotensin is a neuropeptide which exerts a wide spectrum of biological actions on gastrointestinal tissues including gut motility and secretion (Reinecke, 1985; Rothstein and Ouyang, 1989; Unno et al., 1999; Zhao and Pothoulakis, 2006). In addition, neurotensin might also participate in various pathophysiological gastrointestinal processes, including the modulation of intestinal responses to stressful and inflammatory insults (0'Hara et al., 2004; Assimakopoulos et al., 2005; Zhao and Pothoulakis, 2006; Akcan et al., 2008). Moreover, neurotensin stimulates intestinal cell growth (Izukura et al., 1992), acting as a potent cellular mitogen for colorectal and pancreatic cancer (Wang et al., 2006). In this regard we can consider, besides the action of neurotensin on gut motility and its possible involvement in the pathogenesis of intestinal motility disorders, a further role on intestinal epithelium. Previous investigations showed that in atresic chick embryo, operated on D 12, the rapid distension of the bowel until around $D 17$ is associated with the progressive destruction of the epithelium. It may be assumed that despite the persistence of high pressure within the proximal bowel, the destructive and adaptive reactions assume the state of equilibrium around D 18 and in the last stages of incubation regeneration of the epithelium prevails leading eventually the near-normal microscopic appearance of the epithelium (Baglaj et al., 2001).

The modifications of the enteroendocrine cells pattern confirm the involvement of endocrine cells in the complicated pathology of intestinal atresia. We can hypothesize a role of serotonin and neurotensin in the pathophysiology of intestinal motility disorders or in other manifestation related to atresic pathology, or anyway in attempt to repair, such as accelerated development in the proximal bowel or regenerative actions. Our comparative findings in normal and atresic chick embryo small intestine now suggest that the increase of endocrine cells in proximal bowel depends closely on the precociousness of the atresic event and the severity of the intestinal dilation.

\section{Acknowledgements}

The authors thank Mr Simone Iannacone for technical assistance. 


\section{References}

Akcan A, Muhtaroglu S, Akgun H, Akyldiz H, Kucuk C, Sozuer E et al. Ameliorative effects of bombesin and neurotensin on trinitrobenzene sulphonic acid-induced colitis, oxidative damage and apoptosis in rats. World J Gastroenterol 2008; 14:1222-30.

Assimakopoulos SF, Scopa CD, Zervoudakis G, Mylonas PG, Georgiou $C$, Nikolopoulou $\mathrm{V}$ et al. Bombesin and neurotensin reduce endotoxemia, intestinal oxidative stress, and apoptosis in experimental obstructive jaundice. Ann Surg 2005; 241:159-67.

Assimakopoulos SF, Vagianos CE, Charonis AS, Alexandris IH, Spiliopoulou I, Thomopoulos KC et al. Experimental obstructive jaundice alters claudin-4 expression in intestinal mucosa: effect of bombesin and neurotensin. World J Gastroenterol 2006; 12:34105.

Atoji Y, Watanabe H, Nimamoto N, Sugiyama M, Yamamoto Y, Suzuki $\mathrm{Y}$. Neurotensin immunoreactive cells in the gastrointestinal epithelium of the chicken, pigeon and Japanese quail. Eur $\mathrm{J}$ Histochem 1994; 38:65-72.

Baglaj SM, Czernik J, Kuryszko J, Kuropka P. Natural history of experimental intestinal atresia: morphologic and ultrastructural study. $J$ Pediatr Surg 2001;36:1428-34.

Bertrand PP, Kunze WAA, Furness JB, Bornstein JC. The terminals of myenteric intrinsic primary afferent neurons of the guinea pig ileum are excited by 5-hydroxytryptamine-3 receptors. Neuroscience 2000;101:459-69.

Fujimiya M, Okumiya K, Maeda T. Immuno-electron microscopic demonstration of luminal release of serotonin from enterochromaffin cells of rat embryo. Acta Histochem Cytochem 1995;28:555-63.

Fujimiya M, Okumiya K, Kuwahara A. Immunoelectron microscopic study of the luminal release of serotonin from rat enterochromaffin cells induced by high intraluminal pressure. Histochem Cell Biol 1997;108:105-13.

Fiegel HC, Schomberg RA, Roth B, Grasshoff S, Kluth D. Submucosal plexus of dilated gut disappears after ligation in chick embryos: preliminary results. Europ J Pediatr Surg 2006;16:407-10.

Furness JB, Kunze WAA, Clerc N. Nutrient tasting and signaling mechanisms in the gut. II. The intestine as a sensory organ: neural, endocrine and immune response. Am J Physiol Gastrointest Liver Physiol 1999;277:G922-8.

Gershon MD. Review article: roles played by 5-hydroxytryptamine in the physiology of the bowel. Aliment Pharmacol Ther 1999;13 Suppl 2:15-30.

Gershon MD, Tack J. Reviews in basic and clinical gastroenterology. The serotonin signaling system: from basic understanding to drug development for functional disorders. Gastroenterology 2007;132: 397-414.

Grimelius L, Wilander E. Silver stain in the study of endocrine cells of the gut and pancreas. Invest Cell Pathol 1980;3:3-12.

Grosfeld JL, Ballantine TVN, Shoemaker R. Operative management of intestinal atresia and stenosis based on pathologic findings. $J$ Pediatr Surg 1979;14:368-75.

Hamburger $V$ and Hamilton HL. A series of normal stages in the development of the chick embryo. J Morphol 1951;88:49-92.

Inokuchi $H$, Azuma T, Kawai K, Takeuchi Y, Sano Y. Serotonin immunohistochemistry reveals immature EC cells. Histochemistry 1984; 0:517-8.

Khen N, Jaubert F, Sauvat F, Fourcade L, Jan D, Martinovic $J$ et al.
Fetal intestinal obstruction induces alteration of enteric nervous system development in human intestinal atresia. Pediatr Res 2004; 56/6:975-80.

Kulinska-Niedziela I, Paluszak J. Neurotensin-structure, origin and biological function. Postepy Hig Med Dosw 1997;51:329-42.

Izukura M, Evers M, Parekh D, Yoshinaga K, Uchida T, Townsend CM et al. Neurotensin augments intestinal regeneration after small bowel resection in rats. Ann Surg 1992;215:520-6.

Li CY, Ziesmer SC, Lazcano-Villareal 0 . Use of azide and hydrogen peroxide as an inhibitor for endogenous peroxidase in the immunoperoxidase method. J Histochem Cytochem 1987;35:145760.

Masumoto K, Suita S, Nada O, Taguchi T, Guo R, Yamanouchi T. Alterations of the intramural nervous distributions in a chick intestinal atresia model. Pediatr Res 1999;45:30-7.

O'Hara JR, Ho W, Linden DR, Mawe GM, Sharkey KA. Enteroendocrine cells and 5-HT availability are altered in mucosa of guinea pigs with TNBS ileitis. Am J Physiol Gastrointest Liver Physiol 2004;287:G998-1007.

Parisi Salvi E, Vaccaro R, Baglaj SM, Renda T. Nervous system development in normal and atresic chick embryo intestine: an immunohistochemical study. Anat Embryol 2004;209:143-51.

Reinecke M. Neurotensin. Immunohistochemical localization in central and peripheral nervous system and endocrine cells and its functional role as neurotransmitter and endocrine hormone. Prog Histochem Cytochem 1985;16:1-172.

Romanoff AL. The avian embryo: structural and functional development. The MacMillan Company, NY, 1960, pp 430-531.

Rothstein RD, Ouyang A. Mechanism of action of neurotensin at the ileocecal sphincter region. Life Sci 1989;45:1475-82.

Salvi E, Renda T. Immunohistochemical studies on the ontogenesis of some endocrine cells in the chicken antrum and duodenum. Basic Appl Histochem 1986;30:307-16.

Salvi E, Renda T. 5-HT-like immunoreactive cells in chicken intestine: ontogenesis, morphology and topography. Cell Mol Biol 1989a; 35:297-304.

Salvi E, Renda T. Ontogenesis of endocrine cells in the chicken intestine. An immunohistochemical study. Cell Mol Biol 1989b;35:1726.

Schoemberg RA, Kluth D. Experimental small bowel obstruction in chick embryos: effects on the developing enteric nervous system. J Pediatr Surg 2002; 37:735-40.

Soeda J, O'Brian DS, Puri P. Regional reduction in intestinal neuroendocrine cell populations in enterocolitis complicating Hirschsprung's disease. J Pediatr Surg 1993;28:1063-8.

Tibboel D, Molenaar JC, Van Nie CJ. New perspectives in fetal surgery: the chick embryo. J Pediatr Surg 1979; 14:438-40.

Unno T, Komori S, Ohashi H. Characterization of neurotensin receptors in intestinal smooth muscle using nonpeptide antagonist. Eur J Pharmacol 1999;369:73-80.

Wang X, Wang Q, Ives KL, Evers BM. Curcumin inhibits neurotensinmediated interleukin-8 production and migration of HCT 116 human colon cancer cells. Clin Cancer Res 2006;12:5346-55.

Zhao D, Pothoulakis C. Effects of neurotensin on gastrointestinal motility and secretion, and role in intestinal inflammation. Peptides 2006;27:2434-44.

Zhu JX, Wu XY, Owyang C, Li Y. Intestinal serotonin acts as a paracrine substance to mediate vagal signal transmission evoked by luminal factors in the rat. J Physiol 2001;530:431-42. 